\title{
ARTICLE
}

\section{Radiation Protection Officer Certification Scheme: Malaysian Experience}

\author{
Noraishah PUNGUT ${ }^{1 *}$, Noriah MOD ALI ${ }^{2}$, Noraini RAZALI ${ }^{1}$ \\ ${ }^{1}$ Atomic Energy Licensing Board (AELB), Kuala Lumpur, Malaysia, ${ }^{2}$ SSDL, Malaysian Nuclear Agency, Bangi, 43000 \\ Kajang, Selangor, Malaysia
}

\begin{abstract}
In Malaysia, the need for maintaining competency in radiation protection is emerging, focusing on the qualification of Radiation Protection Officers (RPO). Regulation 23 of Malaysian Radiation Protection (Basic Safety Standards) Regulations 1988, requires the applicant to employ an RPO, with the necessary knowledge, skill and training, enabling effective protection of individuals and minimizing danger to life, property and the environment for all activities sought to be licensed. An RPO must demonstrate the knowledge required, by attending RPO courses organised by an accredited agency and pass the RPO certification examination. Maintaining a high level of competency is crucial for future development of safe applications of ionising radiation. The major goal of training is to provide essential knowledge and skills and to foster correct attitudes on radiation protection and safe use of radiation sources. Assessment of the competency is through theoretical and practical examination. A standard criterion on the performance of the individuals evaluated has been established and only those who meet this criterion can be accepted as certified RPO. The National Committee for the Certification of Radiation Protection Officer (NCCRPO), comprising experts in various fields, is responsible to review and update requirements on competency of a certified RPO. With increasing number of candidates (i.e. 701 in 2008) and the international requirement for radioactive source security, it is incumbent upon the NCCRPO to improve the syllabus of the certification scheme. The introduction of a Radiation Protection Advisor (RPA) to provide service and advice to the radiation industry in Malaysia is also seriously considered.
\end{abstract}

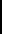

KEYWORDS: radiation protection officer, competency, certification scheme.

\section{Introduction}

The development on the use of atomic energy began with the discovery of x-ray by a scientist named Wilhem Roentgen in Germany in the year 1895. Subsequently, xray was found to have an immediate application in the medical field. The available recorded evidence on the use of x-ray in Malaysia (then Malaya) dated back to 3rd February $1897^{\text {1) }}$, when X-ray was introduced in a hospital in Taiping, Perak. The use of radioactive materials, however, started much later, in the 60 's, where radioiodine and radio phosphorus were introduced in medical diagnosis, therapy and research ${ }^{2)}$. Today, the application of atomic energy has find its way to industries, especially in the engineering field; in Malaysia the use of atomic energy is quite extensive in areas such as ship building, pipe construction, airline maintenance, manufacturing industries and in medicine.

Although activities using atomic energy have prevailed for quite some time in Malaysia, the development in the regulatory and control aspects was quite recent. The first legislation to control the activities using ionising radiation in Malaysia was introduced in 1968 when the Parliament approved the Radioactive Substances Act 1968. However, the rapid expansion of the atomic energy activities in Malaysia needs for more effective control over these activities. Realising the needs for an effective control on the use of atomic energy the Radioactive Substances Act 1968 was repealed and a new Bill called Atomic Energy Licensing Bill was drafted by the Government. The Bill then was approved by the Parliament in April 1984 and gazetted on the June $28^{\text {th }}$ 1984 as Act 304 that is the Atomic Energy Licensing Act. The enforcing authority of this Act is the Atomic Energy Licensing Board (AELB). There were four regulations made under this Act, namely;

a. Radiation Protection (Licensing) Regulations 1986;

b. Radiation Protection (Basic Safety Standard) Regulations 1988;

c. Radiation Protection (Transport) Regulations 1989; and

d. Radiation Protection (Appeals) Regulations 1990. 


\section{Establishment of Atomic Energy Licensing Board}

Following Section 3 of the Act, the Atomic Energy Licensing Board (AELB) was established on $\mathbf{1}^{\text {st }}$ February 1985 as the National Regulatory Authority to enforce the Atomic Energy Licensing Act 1984 ${ }^{3)}$. The AELB's main objective is to regulate and control all activities dealing with atomic energy throughout the country in order to ensure that such activities are being handled safely and do not endanger the radiation workers, members of the public, properties and environment from radiation hazards. To achieve the objective, the AELB is responsible for the following:

a. Authorising the activities related to radioactive materials, nuclear materials and radiation producing devices after appropriate review and evaluation of proposed activity.

b. Conducting inspection (surveillance) and taking enforcement actions to ensure radiation safety requirements are being implemented.

c. Establishing standards and regulations for radiation protection and safe operation pertaining to atomic energy.

The functions of AELB as stated in the Act 304 are as follows:

a. To enforce the Atomic Energy Licensing Act 1984;

b. To advise the Minister and the government of Malaysia on matters relating to the Atomic Energy Licensing Act 1984 and developments pertaining thereto with particular reference to the implications of such developments for Malaysia;

c. To exercise control and supervision over the production, application and use of atomic energy and matters incidental thereto;

d. To establish, maintain and develop scientific and technical co-operation with such other bodies, institutions or organisations in relation to nuclear matters or atomic energy as the Board thinks fit for the purposes of the Atomic Energy Licensing Act 1984;

e. Where so directed by the Government of Malaysia, to perform or provide for the performance of the obligations arising from the agreements, conventions or treaties relating to nuclear matters or atomic energy to which Malaysia is a party where such agreements, conventions or treaties relate to the purposes of the Atomic Energy Licensing Act 1984; and f. To do such other things arising out of or consequential to the functions of the Board under the Atomic Energy Licensing Act 1984 which are not inconsistent with the purposes of this Act, whether or not directed by the Minister.

The AELB has its department to run the above functions and objectives. The Executive Secretary (Director General) holds the highest position in the Department of AELB. The Department consists of six divisions, i.e. Policy, Code and Standards, Assessment and Licensing, Enforcement, Nuclear Installation, Technical Support and the Administration Services. The roles of this division are as follows:

a. The Policy, Code and Standards Division is responsible for the development of laws and subsidiary legislations and providing advisory and information services on the implementation of the Atomic Energy Licensing Act 1984.

b. The Assessment and Licensing Division is responsible for carrying out regulatory research, risk assessment and evaluate license applications.

c. The Enforcement Division is responsible for inspection to ensure compliance of license conditions, carrying out investigation and prosecution, and emergency response and preparedness.

d. Nuclear Installation Division is responsible for the safeguarding of physical security and safety of nuclear material and facility.

e. Technical Support Division is responsible for the supervision of operations at AELB headquarters as well as planning and co-ordinating the administration of the regulatory research laboratory.

f. The Administration Services Division is responsible for providing effective support services to achieve the objectives of the AELB and in carrying out other activities of the AELB, specifically on the management and services, administration and finance.

\section{Establishment of National Committee for the Certification of Radiation Protection Officer}

AELB on the 32 nd meeting that was held on $19^{\text {th }}$ December 1995 has agreed to establish a committee named as National Committee for the Certification of Radiation Protection Officer (NCCRPO). The purposes of establishment of NCCRPO are for assisting AELB in handling matters involving certification of RPO scheme. 
NCCRPO is also responsible in managing matters with the RPO Certification Scheme including examination.

The members of NCCRPO were appointed from several governmental departments, semi-governmental organizations, private organisations, professional associations and individuals whom shall have scientific or technical qualifications relevant to atomic energy or other disciplines connected therewith.

The functions of NCCRPO are as follows:

a. To prepare standard and guidelines for RPO Examinations and RPO Training Center;

b. To prepare questions, standards and guidelines for RPO Examination;

c. To conduct, analyse, inspect and confirm the results of RPO Examination;

d. To conduct audit on the Training Centre and Examination Centre for RPO;

e. To evaluate and endorse applications from agencies wishing to offer radiation protection courses and suggest to the AELB for approval;

f. To evaluate and endorse applications from agencies wishing to be RPO Training Centre and suggest to the AELB for approval;

g. To evaluate and endorse applications from agencies wishing to be RPO Examination Centre and suggest to the AELB for approval; and

h. To look into the possibility of creating a new position ofRadiation Protection Adviser (RPA) and their roles, job specifications, training and examination.

\section{Radiation Protection Officer}

Radiation Protection Officer (RPO) is a technically competent person appointed by the licensee and approved by $\mathrm{AELB}^{3)}$ in writing, to supervise the implementation of appropriate radiation protection regulations; measures and procedures including the radiation protection programme. Regulation 23 of Malaysian Radiation Protection (Basic Safety Standards) Regulations 1988, requires the licensee to employ an RPO, with the necessary knowledge, skill and training, enabling effective protection of individuals and minimizing danger to life, property and the environment for all activities sought to be licensed.

Figure 1 shows the licensee's organizational structure pertaining to radiation protection. It shows that RPO plays major roles to ensure effective of Radiation Protection Programme (RPP) in accordance with the requirements of the regulation dealing with radiation safety and security activities. In general, responsibilities of the RPO are as follows:

a. Implement a radiation protection programme as specified in Figure 2;

b. Implement secure and safe working procedures for normal operation, storage, disposal, transportation and abnormal situations;

c. Supervise the implementation of appropriate radiation protection regulations, measures and procedures.

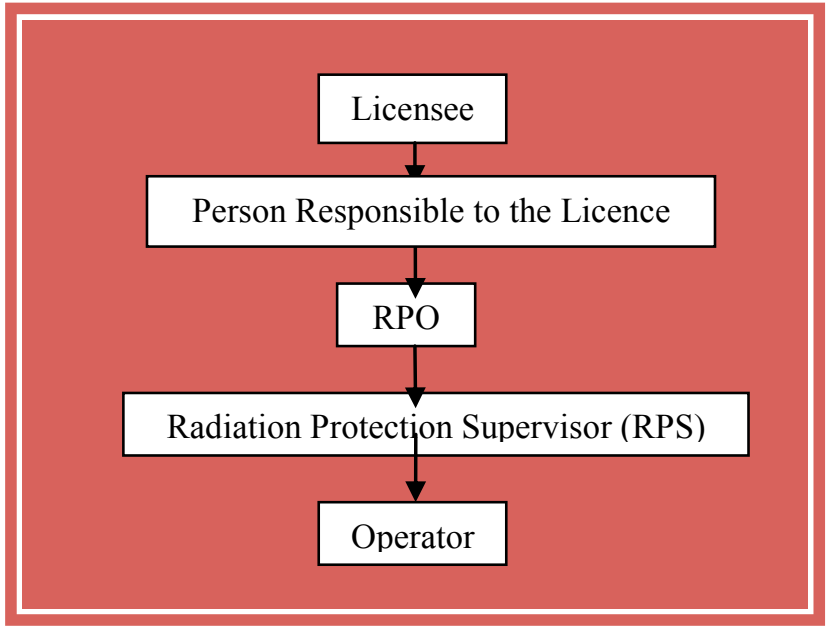

Fig.1 Organisation Structure of Licensee

To ensure effective implementation of RPP, the RPO must demonstrate the knowledge and skill required. It is mandatory for them to attend intensive RPO courses organised by a certified agency and pass the RPO certification examination. The major goal of training is to provide essential knowledge and skills and to foster correct attitudes on radiation protection, secure and safe use of radiation sources. They need to be appointed by their employer before being certified as RPO by the regulatory authority, AELB.

\section{Qualification to Sit for Examination}

Certification of RPO is through sitting for examinations set by AELB. RPO examination is open to candidates with at least one of the following qualifications: 
a. Age at least above 18 year old on the date of application;

b. Have attended RPO training course at the training agency approved by AELB;

c. Have a certificate or diploma or degree; and

d. Have working experience in a particular activity as stipulated in Table 1.

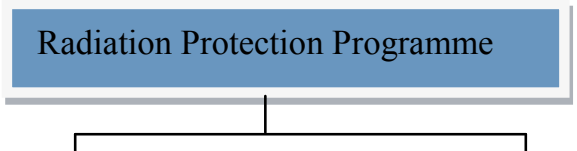

Establishment of programme which include the following: a.The organisational structure pertaining to radiation protection \& security of radioactive sources;

b. The medical surveillance of workers;

c.The personnel monitoring;

d.The area monitoring;

e.The operational limit;

f.The classification of working area;

g. The normal working procedures;

h.The procedures under abnormal situations;

i. The procedures for transportations of a package containing sealed source;

j.The training of a worker; and

$\mathrm{k}$.The procedures for keeping and maintenance of records/documents.

Fig. 2 Outline of Establishment and Implementation of a Radiation Protection Programme

\section{Training Duration and Syllabus}

With increasing number of candidates and the international requirement for radioactive source security, it is incumbent upon the NCCRPO to improve the training duration and syllabus of the RPO certification scheme. Based on their activities, the RPO must attend a minimum training duration (hours) as shown in Table 2. Training duration for a certificate holder is lengthier than for a diploma or degree holder. This is to ensure that the certificate holders are competent and have adequate knowledge, skill and attitude on radiation protection and security of radioactive sources. General and specific technical topic to be covered in the training is as follows:

Table 1 Academic qualification and minimum experience duration (month)

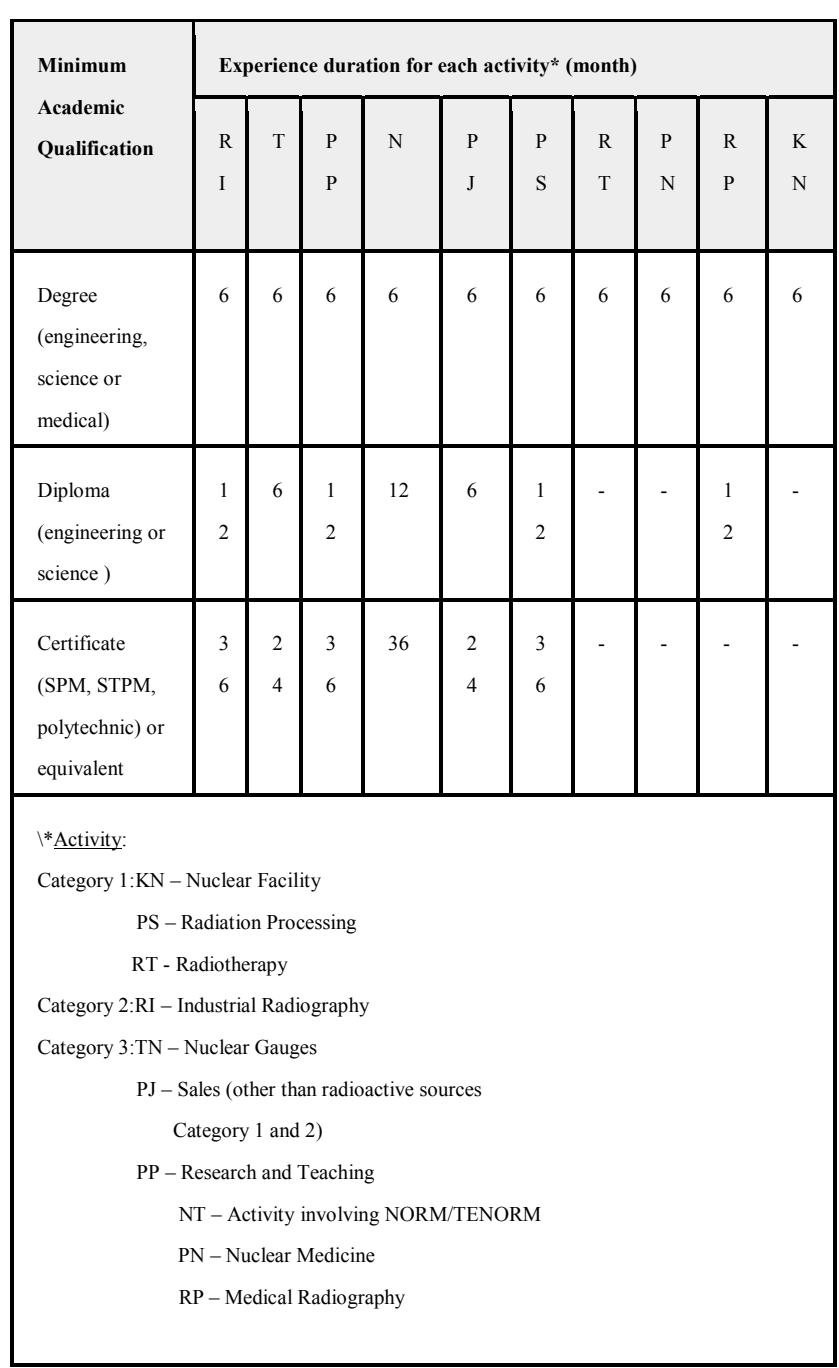

\section{General}

Basic mathematic (2hr)

Fundamentals of ionising radiation $(3 \mathrm{hr})$

Biological effects of radiation ( $2 \mathrm{hr})$

Radiation protection principles $(6 \mathrm{hr})$

Instrumentations and methods in radiological measuring and monitoring (9 hr)

Transportation of radioactive materials $(2 \mathrm{hr})$

Radioactive waste management ( $1 \mathrm{hr})$

Acts and regulations regulating the safe use of atomic energy in Malaysia (2 hr)

Management system of radiation safety and security of radioactive sources $(3 \mathrm{hr})$

Safety in maintenance (1 hr)

Security of radioactive sources $(3 \mathrm{hr}$ ) 


\section{Specific for Industrial Sector}

Safety and security in Category 3 (7 hr)

Planning and emergency procedures in Category $3(5 \mathrm{hr})$

Safety and security in Category $2(8 \mathrm{hr})$

Planning and emergency procedures in Category $2(5 \mathrm{hr})$

Safety and security in Category $1(10 \mathrm{hr})$

Planning and emergency procedures in Category $1(7 \mathrm{hr})$

\section{Specific for Medical Sector}

Safety and security in Category 3 (7 hr)

Planning and emergency procedures in Category $3(4 \mathrm{hr})$

Safety and security in Category $2(10 \mathrm{hr})$

Planning and emergency procedures in Category $2(7 \mathrm{hr})$

Safety and security in Category $1(10 \mathrm{hr})$

Planning and emergency procedures in Category 1 (7 hr)

Table2 Minimum Training Duration (Hour) For Each Activity*

\begin{tabular}{|l|c|c|c|c|c|c|c|c|l|l|}
\hline Activity & R & T & P & N & P & P & R & P & R & K \\
& I & N & P & T & J & S & T & N & P & N \\
\hline Total hour & 46 & 42 & 45 & 44 & 42 & 48 & 50 & 50 & 44 & 51 \\
\hline
\end{tabular}

\section{RPO Examination}

RPO examination must be taken before they can be certified as RPO. After certification of an RPO, the licensee can apply a licence to deal with, own or disposing any radioactive material under the Act 304 . To achieve the above goals, the competency of RPO should be accessed through theoretical and practical examination. Effective on $1^{\text {st }}$ August 2009, RPO examination will conducted based on categorisation of radiation usage. For Category 1 (e.g. radiation processing, nuclear facility and radiotherapy) and 2 (e.g. industrial radiography) of radioactive materials, the candidate should pass practical and theory papers as shown in Fig. 3.

For Category 3, e.g. nuclear gauges, sells other than Category 1 and Category 2, research and teaching, naturally occurring radioactive materials (NORM), technologically enhanced naturally occurring radioactive materials (TENORM), nuclear medicine and medical radiography, the candidate should pass examination as shown in Fig. 4. The result of examination will be endorsed by NCCRPO and approved by AELB.

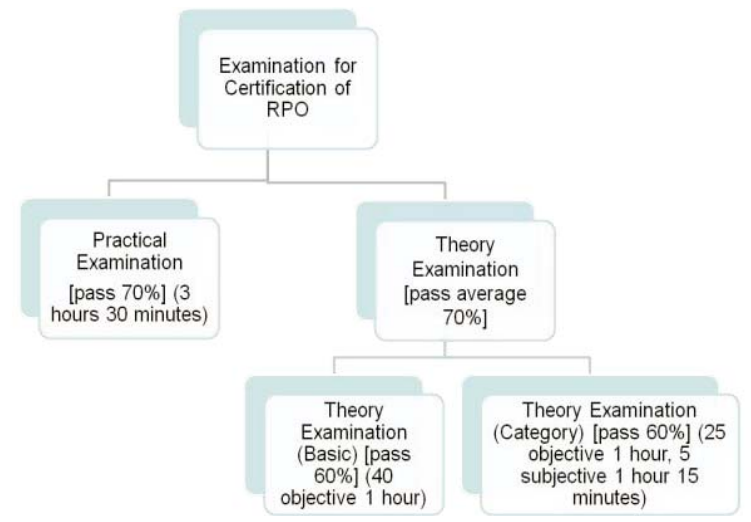

Fig. 3 Structure of RPO Examination for Categories 1 and 2

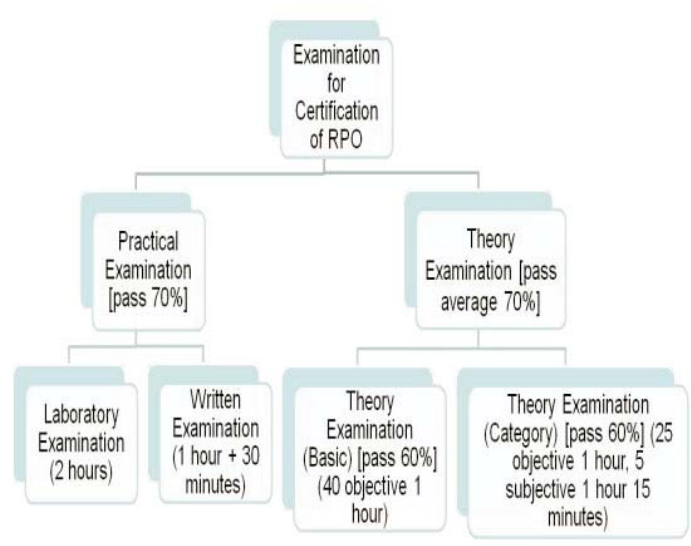

Fig. 4 Structure of RPO Examination for Category 3

A number of candidates sitting for the RPO examination has increased over the years since 2005 until April 2009, as illustrated by Fig. 5. For the year 2008 the percentage of candidates that attended RPO examination increased by $50.9 \%$, compared to 2007 (i.e. $49.1 \%$ increase from 2006).

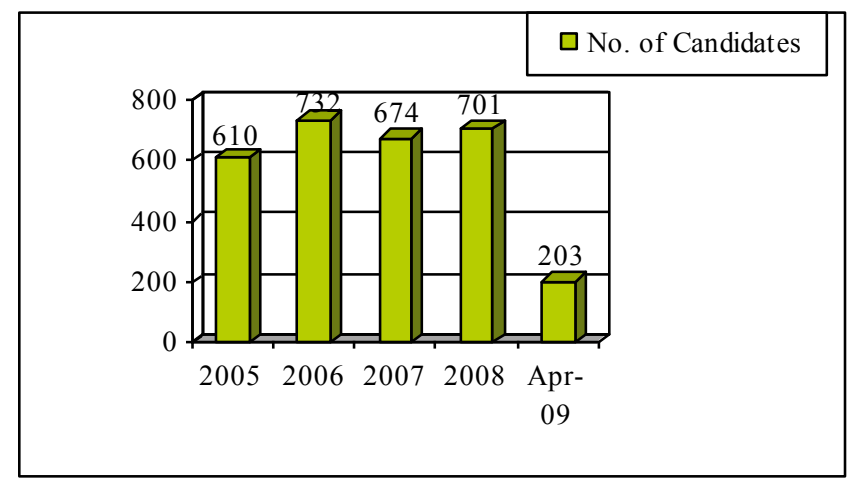

Fig. 5 Number of Candidates Sitting for RPO Examination 
The lower passing mark of the examination was then analysed by NCCRPO, on whether there is a significant effect in terms of academic qualification and experience of the candidate to the examination passing percentage. The statistics shows that academic qualification had significant effect on an RPO's examination result for all activities except industrial radiography, as illustrated in Fig. 6. For gauging, more than $90 \%$ candidates with a degree of science passed RPO examination as compared with diploma $(>25 \%)$ and certificate $(>20 \%)$ candidates.

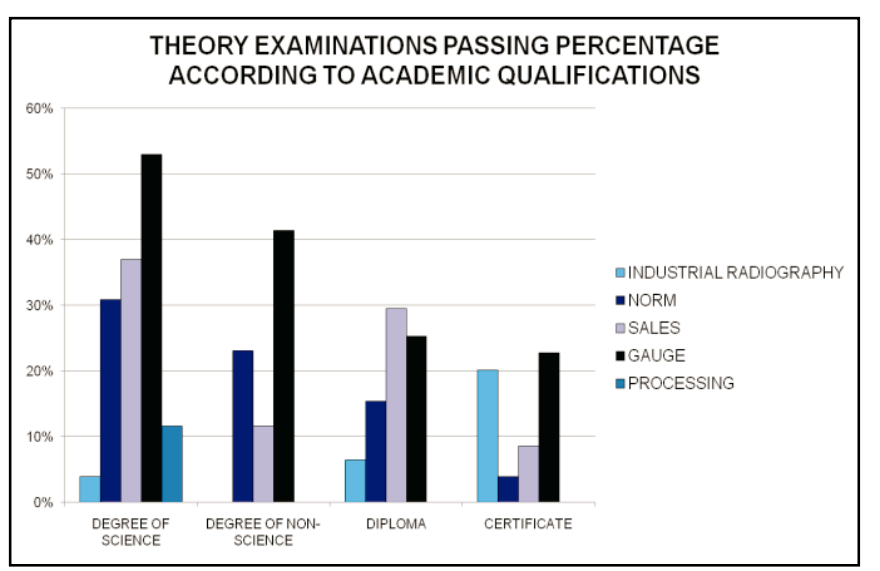

Fig.6 Theory Examinations Pass Percentage According To Academic Qualifications

On the other hand, Fig. 7 shows that working experience had no significant effect on an RPO's examination result for all activities (i.e. more than $35 \%$ one year experience candidate passes RPO examination compared to three years experience candidate $(7.5 \%)$ in gauging activities).

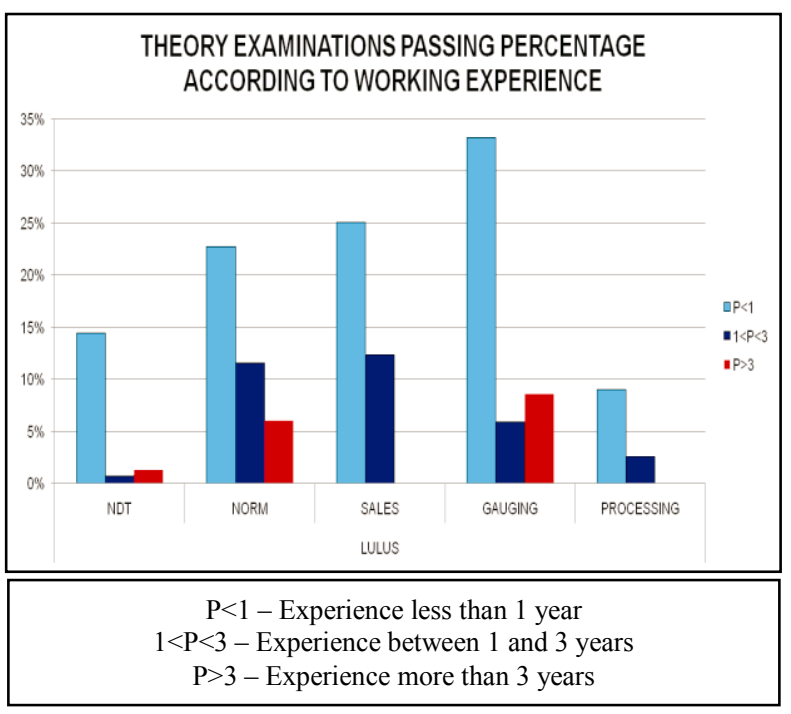

Fig.7 Theory Examination Pass Percentage According To Working Experience

\section{Certified RPO and RPA}

An RPO is a person having competency in carrying out a radiation protection programme and security of radioactive sources within their organisation to ensure workers, members of the public, property and the environment are safe from radiation hazard or exposure. Therefore, an RPO needs to be certified by the AELB based on the following criteria:

a. Age at least above 18 years;

b. Fit to work as Radiation Worker as approved by Approved Registered Medical Practitioner;

c. Possesses RPO course certificate/s;

d. Passed RPO examination; and

e. Registered as radiation worker with AELB.

For the period of $1^{\text {st }}$ January 2006 until $31^{\text {th }}$ December 2008, the total number of RPO that had been certified by AELB was 1674 (Fig. 9). Number of RPO that had been certified in 2007 increased (570) as compared to 2006 (563). Unfortunately, the number of RPO certified in 2008 decreased (541) compared to 2007 (570) due to economic problems in the global environment.

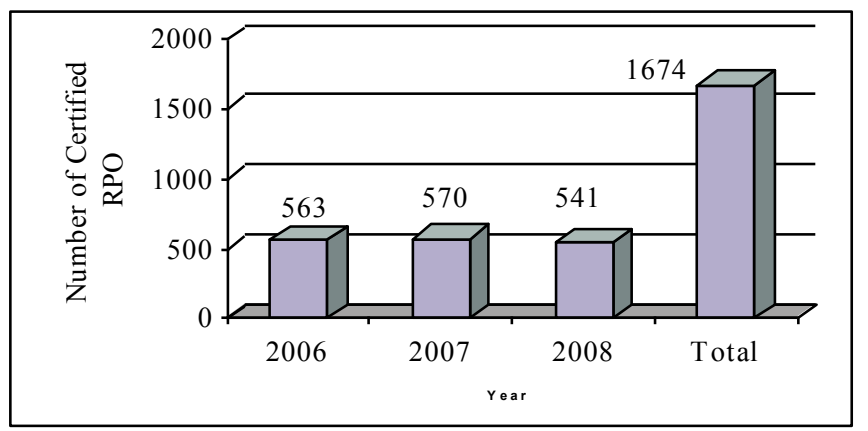

Fig. 9 Number of Certified RPO Issued 2006 -2008

On January 2009, AELB introduced a new post, the Radiation Protection Advisor ( RPA) ${ }^{4}$ to provide service and advice to the radiation and nuclear industry in Malaysia. The criteria of an RPA are more stringent than RPO, as shown in the following:

a. Possesses RPO course certificate/s;

b. Possesses RPO examination certificate/s; 
c. Possesses at least a Master Degree in Science;

d. Registered as radiation worker with AELB;

e. Have submitted a full curriculum vitae;

f. Fit to work as radiation worker as approved by Approved Registered Medical Practitioner;

g. Have at least 15 years experience in radiation protection;

h. Have deep knowledge, expertise and experience in Atomic Energy Licensing Act 1984 (Act 304) and regulations related;

i. Have deep knowledge, expertise and experience in quality, environmental and safety management system; and

j. Have a record as a member of AELB committee or as a radiation protection expert at national and international level or providing advise on radiation protection and regulatory requirements as an expert to at least 5 companies.

\section{Conclusion}

Since the establishment of AELB, according to Section 3 of Atomic Energy Licensing Act 1984, the RPO Certification Scheme in Malaysia has improved. The competency of RPO has been upgraded and maintained from time to time through examination and RPO courses in line with national and international requirements. RPO and RPA with excellent competency need to be nominated by the licensee and certified by the AELB to ensure workers, public, properties and the environment are safe from radiation hazards.

\section{References}

1) $\mathrm{Hj}$ Idris $\mathrm{Hj}$ Hussin, Journal of the Malaysian Society of Radiographers, December 1979.

2) Wharton, R.H. Medical Journal Malaysia 17, 1, 1962.

3) Atomic Energy Licensing Act 1984 (Act 304).

4) Abdul Aziz Tajuddin, RPO Competency in Malaysia, Radiation Protection Conference and Workshop, Kota Kinabalu, 9-10 June 2009. 